\title{
Modification of acoustic and nociceptive reflexes in the rat by visual stimulation
}

\author{
B. L. ASH, T. PARISI, and J. R. ISON \\ University of Rochester, Rochester, New York 14627
}

\begin{abstract}
Three experiments demonstrated in the rat that the flexor reaction to a nociceptive cutaneous stimulus (a .5-msec, .5-mA electric shock to the feet) was inhibited by a preceding light flash. In the first, the optimal lead time was at 50 or $100 \mathrm{msec}$ compared to separations of 5 or $400 \mathrm{msec}$. In the second, the inhibitory effect was shown in ambient noise approximating threshold, indicating that the response decrement was not caused because the light may have blocked a facilitating effect of a moderate background noise level. In the third experiment, the light flash inhibited both the flexor reaction to the cutaneous stimulus and to an acoustic startle stimulus with which it was randomly intermixed. These findings reveal that inhibition is not specific to a particular modality of eliciting stimulus input, though it may be restricted to a particular class of motor events, that is, to flexor reactions.
\end{abstract}

The experiments reported here show in the rat that a flexor withdrawal or flinch reflex to a brief nociceptive stimulus can be inhibited if that eliciting stimulus is preceded by a light flash. Past research on reflex modification in the rat has investigated only modification of the startle reaction to an intense acoustic stimulus. Hoffman and Wible (1970), Ison and Hammond (1971), and Pinckney (1976), amongst others, have shown that preliminary stimuli $\left(\mathrm{S}_{1}\right)$ in auditory, visual, and cutaneous modalities inhibit startle to the acoustic burst $\left(S_{2}\right)$ if they are introduced with an appropriate lead time. The optimal temporal interval is in the vicinity of 50 $100 \mathrm{msec}$. The acoustic startle reaction is manifest as a rapid contraction of the flexor musculature resulting in a momentary crouching posture. A similar flexor pattern appears in the rat in response to a brief nociceptive cutaneous stimulus produced by applying an electrical charge across floor plates upon which the animal stands. This flinch response may also be a startle reaction (Hoffman, Fleshler, \& Abplanalp, 1964 ), or it may be a generalized flexor withdrawal response that is organized at the spinal level rather than, as is the case for the acoustic startle, in the brainstem (Szabo \& Hazafi, 1965). That it is a directional withdrawal reaction is suggested to us by our failure, in pilot experiments, to detect its presence following tailshock rather than footshock. In either case, however (and this is the reason for the present work), it is a reflex which shares an efferent limb with the acoustic startle reflex, but has a

This research was supported by a research grant from the Public Health Service, 1RO1 NS-12443. Reprints may be obtained from Professor James R. Ison, Department of Psychology, Psychology Building, University of Rochester, Rochester, New York 14627. different afferent limb. Thus, an examination of its susceptability to modification by preliminary stimuli may help to illuminate the level at which reflex modulation occurs between the two stimuli. It should be noted that the light flash does not itself elicit detectable flexor reactions.

\section{EXPERIMENT 1}

This experiment was designed to reveal whether a visual stimulus (a light flash) could inhibit the rat's flinch response to an electric shock delivered to the floor of the cage, and to describe the course of inhibition as determined by variation in the interval between the two stimuli.

\section{Method}

Subjects. The animals were six male albino rats obtained from the Holtzman Co., Madison, Wisconsin, weighing from 405 to $496 \mathrm{~g}$ at the time of testing. Two had been subjects previously in an experiment concerned with sound-induced modification of the acoustic startle reaction. Food and water were available ad lib in the home cages. Animals were run during the dark period of a reversed $12 \mathrm{~h}$ light/dark cycle.

Apparatus. The animals were run in a small cage $(16.3 \times 7.0$ $\times 9.5 \mathrm{~cm}, 6-1 / 2 \times 2-3 / 4 \times 3-3 / 4$ in.) with brass rod sides and a floor made of two steel plates separated by $1.2 \mathrm{~cm}(1 / 2$ in.). The cage was held firmly in a frame with compression springs. Four 6-V light bulbs, run on $28 \mathrm{~V}$, were mounted one on each corner of the cage. When run at $28 \mathrm{~V}$ for a nominal duration of $4 \mathrm{msec}$, they provided a light flash that reached a peak intensity of $45 \mathrm{fc}$ in $1 \mathrm{msec}$. This peak lasted for $10 \mathrm{msec}$ and there followed a decline in intensity of an approximate decay function over the next $30 \mathrm{msec}$. A white-noise background of $70 \mathrm{~dB}$ (re: $20 \mu \mathrm{N} / \mathrm{m}^{2}$ ) was provided by a Grason-Stadler white-noise generator, the output of which fed two 4-in. cone speakers. Electric shock stimuli were delivered to the two plates of the cage from a Grass SD5, passed through a Grass constant current unit. The nominal shock intensity was $2 \mathrm{~mA}$; the measured intensity with a subject in place was $.5 \mathrm{~mA}$. An accelerometer mounted on the cage detected the animal's reaction to the shock. The output of the accelerometer 
was amplified on a Beckman dynograph, and the response was read as peak-to-peak deflection in millimeters. Stimuli were controlled by electronic timers. The animal cage and stimulus devices were placed in an Industrial Acoustic Company soundattenuating room. Stimulus control, timing gear, and recording apparatus were in a nearby room.

Procedure. Each animal was placed in the apparatus for a 3-min adaptation period which was followed by 3 shock-alone trials. There followed a series of 36 trials, of which 6 were shock-alone control trials and 30 were paired light-shock trials, 6 at each of the following interstimulus intervals: 5, 50, 100, 500, and $1,000 \mathrm{msec}$, measured from onset to onset. The animal's resistance measured across the plates was monitored, and trials were not given if the resistance was too low, indicating that the animal had urinated, or too high, indicating that it had adopted some peculiar position. These occurrences were rare, and no animal learned to avoid shock. The order of trials was such that each block of 6 trials contained a trial of each type, and the placement of that type within the block varied across blocks. Intertrial intervals ranged from 15 to $40 \mathrm{sec}$, with a mean of about $30 \mathrm{sec}$.

\section{Results and Discussion}

Table 1 presents the mean reflex amplitudes in each condition for each of the six animals and for the group as a whole. All animals exhibited an intermediate trough in response amplitudes; for four, the minimum amplitude was at the 100 -msec separation, for one it was at the 50-msec separation, and for one it was at the $500 \mathrm{msec}$ separation. For the group as a whole, maximal inhibition was obtained with the 100 -msec interval, where, averaged across individual values, the mean response was $34.3 \%$ less than that obtained at the $S_{2}$-alone control baseline. Analysis of variance of the data displayed in Table 1 yielded a main effect of stimulus conditions $(F=4.78$, $\mathrm{df}=5 / 25, \mathrm{p}<.005)$. Subsequent $\mathrm{t}$ tests showed that the mean amplitude obtained at the $100-\mathrm{msec}$ separation between the stimuli differed $(p<.05)$ from the means obtained in all of the other conditions save that obtained at the $50-\mathrm{msec}$ separation. These data demonstrate that a visual stimulus will inhibit the flinch reaction to a nociceptive cutaneous stimulus provided by a brief electric shock. The temporal function obtained approximates that showing the development and decay of inhibition for the acoustic startle in the rat, as well as those functions obtained with cutaneously elicited eyewink reflexes in rabbits (Ison \& Leonard, 1971) and humans (Krauter, Leonard, \& Ison, 1973). The similarity of these diversely obtained behavioral relationships suggests that the responsible mechanisms have a considerable range of application.

\section{EXPERIMENT 2}

By showing that a nociceptive cutaneous flexor reflex was inhibited by a visual stimulus, Experiment 1 would appear to have shown that a reflex modification in the rat is not restricted to reflexes that involve acoustic processes. However, a role for such processes can be still imagined, in a more complicated argument suggested to us by Davis (Note 1). It is known that, in the rat, a variety of reflexes are facilitated in the presence of moderately intense white-noise-elicited reflexes, such as the acoustic startle pattern (Hoffman \& Searle, 1965) and the nociceptive flexor response (Russo \& Ison, Note 2), as well as more complicated behavior patterns, such as shock-elicited aggression (Sheard, Astrachan, \& Davis, 1975) and operant behaviors (MacMillan, Gray, \& Ison, 1972). Possibly, preliminary stimuli may interfere with this noise-produced reflex enhancement and thus produce an apparent inhibitory effect by means of "defacilitation." If this were the case, then one would not expect inhibition to occur in a condition in which facilitation were absent-if, for example, the experiment were run in the absence of any imposed noise background. In this experiment, then, the test for reflex modification was performed under an ambient level which approximated threshold for the rat (Hoffman \& Wible, 1970).

\section{Method}

Subjects. The animals were six male albino rats from the same population as that used in Experiment 1.

Apparatus. The apparatus was the same as that used previously, except that the response was recorded from a digital voltmeter which integrated the output of the polygraph over a $100-\mathrm{msec}$ epoch beginning with the onset of $\mathrm{S}_{2}$.

Procedure. Each subject received a 5 -min period in the test chamber followed by a $2 \mathrm{~S}_{2}$-alone trials, these constituting an adaptation phase. There followed a series of 32 trials, $16 \mathrm{~S}_{2}$-alone, and $16 S_{1}-S_{2}$ in which $S_{2}$ was preceded at a lead time of $50 \mathrm{msec}$ by a light flash. Trial types were given randomly with a constraint that no more than 2 of the same sort were given successively. Procedural details and other stimulus values were the same as used in Experiment 1, with the exception that the ambient noise level was about $27 \mathrm{~dB}$ (re: $20 \mu \mathrm{N} / \mathrm{m}^{2}$ ).

Table 1

Mean Response Amplitudes (Millimeters)

\begin{tabular}{cccccccc}
\hline & \multicolumn{7}{c}{ Condition } \\
\cline { 2 - 7 } Subject & $\mathrm{S}_{2}$ & $\mathrm{~S}_{1} 5 \mathrm{~S}_{2}$ & $\mathrm{~S}_{1} 50 \mathrm{~S}_{2}$ & $\mathrm{~S}_{1} 100 \mathrm{~S}_{2}$ & $\mathrm{~S}_{1} 500 \mathrm{~S}_{2}$ & $\mathrm{~S}_{1} \mathbf{1 0 0 0 \mathrm { S } _ { 2 }}$ \\
\hline 1 & 45.2 & 31.8 & 26.8 & 35.8 & 38.7 & 51.8 \\
2 & 34.8 & 39.3 & 24.7 & 21.2 & 35.5 & 37.0 \\
3 & 52.3 & 39.5 & 53.3 & 35.0 & 39.7 & 51.0 \\
4 & 32.0 & 32.3 & 18.7 & 12.3 & 27.5 & 25.7 \\
5 & 62.3 & 71.3 & 48.2 & 31.8 & 59.0 & 72.7 \\
6 & 21.7 & 29.0 & 35.2 & 21.2 & 16.2 & 29.8 \\
Mean & 41.4 & 40.5 & 34.5 & 26.2 & 35.9 & 45.0 \\
\hline
\end{tabular}




\section{Results and Discussion}

Table 2 presents the mean reflex amplitudes in each condition for each of the six subjects and for the group as a whole. The difference in the means for the group was reliable $[t(5)=3.56, p<.01]$, indicating that the light flash did inhibit the reflex. Reflex amplitudes to the shock in five of the six animals were reliably reduced by the preceding light flash (in the $t$ tests, the trial number was used to pair $S_{2}$-alone and $S_{1}-S_{2}$ trials), whereas the behavior of one animal was unaffected by $S_{1}$. Whether an effect would have been obtained at a different interval, or whether, perhaps, this idiosyncratic animal was blind is unfortunately unknown. For the five positive subjects, the response to the cutaneous stimulus preceded by the light ranged from $26 \%$ to $46 \%$ below the control value, values which approximate that found in Experiment 1. We conclude that the depressing effect of $S_{1}$ on the reaction to $S_{2}$ does not depend on the prior imposition of a moderately intense background noise level or the facilitatory process which accompanies such acoustic stimulation.

\section{EXPERIMENT 3}

The question in this third experiment was whether a visual stimulus could inhibit the reflex expression of eliciting stimuli from two modalities when these two are presented in random order. In all prior experiments on reflex expression going back to Sechenov (1863), some single reflex was the object of study and reflex modulation was described with respect to that one reflex. Only if one considers the literature in the aggregate can statements be made which have some apparent generality: stimulus events momentarily engage an inhibitory process which can be detected by its decremental effect on any reflex elicited in its presence. This statement describes a limitation in an organism's processing of motor output which must have profound functional significance, especially so since the phenomenon on which it is based has been observed in a number of species, including members of the class Amphibea (frogs) and those of order Primates (humans). That any single report describes the phenomenon for only one specific reflex is a barrier to broad conceptualization. A demonstration that a single $S_{1}$ will inhibit reflex expression to two interspersed eliciting stimuli in different modalities does not demand the assumption that $S_{1}$ engages a general inhibitor. But if the attempt is successful, then it must be assumed that the inhibitory process engaged on any one trial is not tied to any one sort of subsequent eliciting stimulus. In this sense, it can be thought of as a nonspecific inhibitor.
Table 2

Mean Response Amplitudes (Millivolts) on $S_{2}$-Alone and $S_{1}-S_{2}$ Trials

\begin{tabular}{ccc}
\hline & \multicolumn{2}{c}{ Condition } \\
\cline { 2 - 3 } Subject & $\mathrm{S}_{2}$ & $\mathrm{~S}_{1} 50 \mathrm{~S}_{2}$ \\
\hline 1 & 6.22 & $3.69^{*}$ \\
2 & 2.33 & $1.73^{*}$ \\
3 & 5.11 & $2.78^{*}$ \\
4 & 3.56 & $2.08^{*}$ \\
5 & 1.43 & 1.48 \\
6 & 4.45 & $2.40^{*}$ \\
Mean & 3.85 & 2.36 \\
\hline
\end{tabular}

${ }^{*} p<.05$

\section{Method}

Subjects. The rats were of the same sort used previously. Five were naive and one had been a subject in a previous experiment on auditory preliminary stimuli and acoustic startle reactions.

Apparatus. The prior setup was modified with the addition of a tweeter to deliver an acoustic startle stimulus, $110-\mathrm{dB}$ tone of $10 \mathrm{kHz}, 20 \mathrm{msec}$ long, with a $5-\mathrm{msec}$ rise and decay time. It was generated by a Hewlett-Packard oscillator and controlled by an electronic switch. Response amplitude was taken from the digital voltmeter. Response latency was read off a storage CRT, which triggered off delivery of the eliciting stimulus. The oscilloscope was run at a fast sweep $(5 \mathrm{msec} / \mathrm{cm})$ and high gain to provide resolution of the initial deviation from baseline produced by the response. Readings of reaction latency were discriminable to within $1 \mathrm{msec}$.

Procedure. Each animal received 64 trials, 16 in each of four conditions. Control trials consisted of either an acoustic tone burst or the electric shock. Two sorts of paired trials inserted the light flash before each of these stimuli. The interstimulus interval was $50 \mathrm{msec}$, and intertrial intervals, run as before, averaged $30 \mathrm{sec}$. The order of trials was taken from a sequence of four 4 by 4 Latin square orders, different for each animal. Animals began the experiment with a 5 -min adaptation period then 4 warm-up control trials, 2 to each stimulus.

\section{Results and Discussion}

Table 3 presents the mean integrated response amplitudes and latencies for each animal for each of the four conditions. It is apparent that the visual stimulus was able to inhibit the reaction to the auditory stimulus and to the cutaneous stimulus, as under both paired conditions response amplitudes were reduced and response latencies increased compared to the control values. Three-way analyses of these data, using Subjects, Stimulus Modality, and Paired vs. Single Trials as factors yielded reliable effects only for the difference between control trials and paired trials; for amplitude, $F(5,23)=44.46, p<.01$, and for latency, $F(5,33)=38.33, p<.01$. Individual $t$ tests on each condition were performed for each animal. Reliable differences $(p<.05)$ are starred in Table 3.

Two implications of these data are apparent. First, they reveal that prior demonstrations of reflex inhibition in the rat are not tied to procedures in which an 
Table 3

Mean Amplitudes (Millivolts) and Latencies (Milliseconds) on $S_{2}$-Alone and $S_{1}-S_{2}$ Trials for Acoustic and Cutaneous $S$ timuli

\begin{tabular}{|c|c|c|c|c|c|c|c|c|}
\hline \multirow[b]{3}{*}{ Subject } & \multicolumn{4}{|c|}{ Acoustic } & \multicolumn{4}{|c|}{ Cutaneous } \\
\hline & \multicolumn{2}{|c|}{ Amplitude } & \multicolumn{2}{|c|}{ Latency } & \multicolumn{2}{|c|}{ Amplitude } & \multicolumn{2}{|c|}{ Latency } \\
\hline & $\mathrm{S}_{2}$ & $s_{1}-s_{2}$ & $S_{2}$ & $S_{1}-S_{2}$ & $\mathrm{~S}_{2}$ & $S_{1}-S_{2}$ & $S_{2}$ & $S_{1}-S_{2}$ \\
\hline $\begin{array}{l}1 \\
2 \\
3 \\
4 \\
5 \\
6\end{array}$ & $\begin{array}{l}2.79 \\
1.98 \\
2.37 \\
1.38 \\
3.22 \\
1.95\end{array}$ & $\begin{array}{c}1.44^{*} \\
1.07^{*} \\
.79^{*} \\
.95 \\
1.03^{*} \\
.52^{*}\end{array}$ & $\begin{array}{l}19.1 \\
20.6 \\
19.5 \\
20.4 \\
17.1 \\
19.3\end{array}$ & $\begin{array}{l}20.4^{2} \\
21.7^{*} \\
23.7^{*} \\
23.2^{*} \\
20.8^{*} \\
23.1^{*}\end{array}$ & $\begin{array}{r}1.18 \\
1.80 \\
1.01 \\
2.80 \\
2.46 \\
.66\end{array}$ & $\begin{array}{c}1.04 \\
.51^{*} \\
.45^{*} \\
1.62^{*} \\
1.20^{*} \\
.62\end{array}$ & $\begin{array}{l}22.4 \\
21.1 \\
21.3 \\
20.1 \\
19.5 \\
18.3\end{array}$ & $\begin{array}{l}23.4 \\
26.4^{*} \\
21.9 \\
21.6^{*} \\
19.1 \\
21.8^{*}\end{array}$ \\
\hline Mean & 2.28 & .97 & 19.3 & 22.2 & 1.65 & .91 & 20.4 & 22.4 \\
\hline
\end{tabular}

${ }^{*} p<.05$

acoustic reflex is elicited or those in which only a single test reflex is used. In this regard, the data supplement a prior finding of Ison and Krauter (1975) that startle reflex inhibition can be obtained when the rat is engaged in consummatory activity. The phenomenon occurs both in situations in which animals are engaged in other behaviors and in situations in which multiple reflexes are elicited. This increases the likelihood that the phenomenon is present outside of the laboratory and that it plays an important role in reflex control during an animal's commerce with its natural environment. The second inference we draw from these data is that because the visual stimulus inhibited reflexes elicited by stimuli in both an auditory and a cutaneous modality, the mechanism by which the effect is accomplished must transcend devices available to just one modality. Although one might propose that the terminal mechanisms are relatively peripheral for each modalityas, for example, some sort of efferent damping of afferent input-control over both modalities could only be accomplished by some more central process which functioned as a general inhibiting gate. Other information (e.g., Ison \& Krauter, 1974) makes it more likely that the machinery affects motor output rather than stimulus input, and, beyond this, we note that both reflexes used in the present work involve approximately the same general flexion reaction. Perhaps the most cautious statement which is permitted by the effects observed so far is that reflex involvement of the flexor musculature is inhibited by stimuli presented just prior to reflex elicitation.

\section{REFERENCE NOTES}

1. Davis, M. Personal communication, 1975.

2. Russo, J., \& Ison. J. R. Positive and negative effects of backgnound noise on reflex behavior. Manuscript in preparation.

\section{REFERENCES}

Hoffman, H. S., Fleshler, M., \& Abplanalp, P. L. Startle reaction to electrical shock in the rat. Jourmal of Comparative and Physiological Psychology, 1964, 58, 132-139.

Hoffman, H. S., \& Searle, J. L. Acoustic variables in the modification of the startle reflex in the rat. Journal of Comparative and Physiological Psychology, 1965, 60, 53-58.

Hoffman, H. S., \& Wible, B. L. Role of weak signals in acoustic startle. Journal of the Acoustical Society of America, 1970 , 47, 489-497.

Ison, J. R., \& Hammond, G. R. Modification of the startle reflex in the rat by changes in the auditory and visual environments. Journal of Comparative and Physiological Psychology, 1971, 75, 435-452.

Ison, J. R., \& Krauter, E. E. Reflex inhibiting stimuli and the refractory period of the acoustic startle reflex in the rat. Journal of Comparative and Physiological Psychology, 1974, 86, 420-425.

Ison, I. R., \& KRAUTER, E. E. Acoustic startle reflexes in the rat during consummatory behavior. Journal of Comparative and Physiological Psychology, 1975, 89, 39-49.

IsON, J. R., \& LEONARD, D. W. Effects of auditory stimuli on the amplitude of the nictitating membrane reflex of the rabbit (Oryctolagus cuniculus). Journal of Comparative and Physiological Psychology, 1971. 75, 157-164.

Krauter, E. E., Leonard, D. W., \& Ison, J. R. Inhibition of the human eyeblink of a brief acoustic stimulus. Journal of Comparative and Physiological Psychology, 1973, 84, 246-251.

MacMillan, A. Sr. C., Gray, J. A., \& Ison, J. R. An apparent new instance of stimulus intensity dynamism during discrimination of duration of repeating auditory stimuli. Quarterly Journal of Experimental Psychology, 1973, 25, 62-70.

Pinckney, L. A. Inhibition of the startle reflex in the rat by prior tactile stimulation. Animal Learning \& Behavior, 1976, 4. 467.472.

Sechenov, I. M. Reflexes of the brain. Cambridge: MIT Press, 1965. (Trans. S. Belsky; original publication St. Petersburg: Suchchinskii, 1863.)

Sheard, M. H., Astrachan, D. I., \& Davis, M. Effect of noise on shock elicited aggression. Nature, 1975, 257, 43-44.

Szabo, I., \& Hazafi, K. A. Elicitability of acoustic startle reaction with brain stem lesions. Acta Physiologica Academiae Scientiarum Hungericae, 1965, 27, 155-165.

(Received for publication February 22, 1977; revision accepted June $13,1977$. ) 